\title{
HACIA UN INSTITUCIONALISMO SALVAJE
}

\author{
Towards a Savage Institutionalism
}

\section{RESUMEN}

Este trabajo interroga la condición destituyente de las revueltas chilenas y su aparentemente paradójica propuesta de una nueva Constitución, en relación con la crisis general de la gobernabilidad neoliberal contemporánea, y en relación con el agotamiento del modelo juristocrático que ha mantenido capturado al país desde la misma instauración de la Constitución de 1980. El trabajo propone un institucionalismo salvaje basado en una concepción prostética y suplementaria de la ley y de las instituciones, orientada hacia una historicidad del ser en común capaz de profanar la ficción soberana y desbaratar el fetiche de la supuestamente ejemplar transición chilena a la democracia. A partir de esto, el trabajo problematiza la misma forma constitucional, disputando con el "nuevo constitucionalismo espiritual" chileno el estatuto mismo del derecho y su relación con el "pueblo".

Palabras claves: Institucionalismo salvaje; Juristocracia; Constitucionalismo espiritual; Duopolio; Criollismo tardío.
UNIVERSUM

Revista de Humanidades y Ciencias Sociales

\section{SERGIO VILLALOBOS- RUMINOTT}

Profesor de Estudios

Latinoamericanos, Universidad de Michigan, Estados Unidos.

Correo electrónico:

svillal@umich.edu

ORCID: 0000-0002-9570-6780

ResearchGate:

Scholar.google:

Academia.edu:SergioVillalobosRuminott

Artículo recibido el 6 de mayo, 2020. Aceptado el 22 de junio, 2020.

DOI:

Web: http://universum.utalca.cl | ISSN: 0716-498X - 0718-2376 


\begin{abstract}
This work interrogates the destituent condition of the Chilean revolts and their "paradoxical" call for a new Constitution, in relation to the general crisis of contemporary neoliberal governability, and, in relations to the exhaustion of the juristocratic model that has limited Chilean democracy since the instauration of the 1980 Constitution. The article proposes the necessity of a savage institutionalism based on a prosthetic and supplementary conception of the law and the institutions, oriented towards a radical historicity of the being-in-common able to desecrate the sovereign fiction and to deactivate the fetishist narrative about the exemplary Chilean transition to democracy. Finally, the article problematizes the emergence of a new Constitutionalism in the country, namely a spiritual one, and disputes with it the reference to the "people".
\end{abstract}

Keywords: Savage Institutionalism; Juristocracy; Spiritual Constitutionalism; Duopolic Formation; Late Criollism.

De momento, quisiera tan sólo entender cómo pueden tantos hombres, tantos pueblos, tantas ciudades, tantas naciones soportar a veces a un solo tirano, que no dispone de más poder que el que se le otorga, que no tiene más poder para causar perjuicios que el que se quiera soportar y que no podría hacer daño alguno de no ser que se prefiera sufrir a contradecirlo. Es realmente sorprendente $-\mathrm{y}$, sin embargo, tan corriente que deberíamos más bien deplorarlo que sorprendernos- ver cómo millones y millones de hombres son miserablemente sometidos y son juzgados, la cabeza gacha, a un deplorable yugo.

Étienne de la Boétie, El discurso de la servidumbre voluntaria ${ }^{1}$

\title{
LA FICCIÓN DE LA LEY
}

Atendida en su forma inmediata, la pregunta de Étienne de la Boétie podría ser perfectamente reformulada así: ¿porqué los hombres, muchos

1 2008, páginas 45-46. 
hombres, casi todos, deciden obedecer a uno? La actualidad indesmentible de la pregunta, elaborada por un joven de la Boétie en 1577, consiste en aproximarse al fenómeno del poder de una manera diametralmente opuesta a como se aproximaría un teórico o un estudioso; para él, no se trata de describir el funcionamiento, las reglas o las normas que aseguran el vínculo de obediencia y subordinación, vínculo que asociamos con la soberanía, la legitimidad o la autoridad; sino, por el contrario, su pregunta apunta al carácter inverosímil de la dominación y la obediencia. Haber hecho posible esta pregunta como pregunta constituye, en sí mismo, un acto instituyente y radical, pues suspende la petitio principii de la autoridad, exponiéndola a la cuestión misma de su (falta de) fundamento. En efecto, la autoridad no podría exigir obediencia sin que ella fuese, desde antes, percibida como autoridad, ya sea como producto de la imposición (la fuerza), la convicción (la fe) o de la ley (la razón y la fuerza). Pero ¿qué le otorga a la autoridad su condición de autoridad?, ¿a qué tiempo inmemorial se refiere ese "antes" que hace posible la demanda de obediencia? El estatuto de ese tiempo inmemorial, de ese "antes", es precisamente el núcleo de lo que podemos llamar "la ficción soberana", y sería esa ficción la que queda expuesta con la pregunta formulada por de la Boétie.

En otras palabras, la pregunta interroga la misma producción de una relación de sujeción legitimada, retro-proyectivamente, por una narrativa contractual que apela a un contrato social firmado in illo tempore; un tiempo inverosímil que se ubica justo antes del comienzo del tiempo histórico, haciéndolo posible como tiempo de la ley, del Estado y de la política. ${ }^{2}$ Nunca nadie asistió a ese momento inmemorial, pero es él el que determina la historicidad de la ley y del poder. Romper con esa determinación, con esa ficción, pareciera ser lo que el Discurso de la servidumbre voluntaria sutilmente

2 Sería desde ese tiempo del "después" producido por la postulación hipotética de un "antes", desde donde hacemos la experiencia de la ley como si siempre estuviésemos ante ella, en la media en que ella está ya ahí, antes que nosotros. Más allá de la serie de referencias contemporáneas, véase el famoso relato de Kafka, "Ante la ley” (1999) como parábola de esta auto-fundamentación del derecho moderno. 
siguiere como posibilidad de un institucionalismo radical o salvaje. Es más, de la Boétie anticipa el contractualismo hobbesiano y lo radicaliza, mostrando que la retirada del fundamento teológico del poder solo nos deja, como diría Lefort, con un vacío que la práctica instituyente de los hombres intentara suturar. El nombre de esa sutura, siempre momentánea, es, precisamente, política y no derecho. ${ }^{3}$

Dicho institucionalismo salvaje, por lo tanto, no implica la simple cancelación del orden, del Estado o de las instituciones, sino la historización radical de toda narrativa que funcione como ficción soberana de la autoridad, es decir, de toda narrativa que pretenda un acceso privilegiado a aquel "origen absoluto" e inverosímil que determina el recorte temporal en el que se inscribiría el tiempo de la historia y de la política. Tal institucionalismo, pensado en términos genealógicos, se opone a la filosofía normativa de la historia y del derecho preguntándose no por la verdad de ese pasado originario, sino por el pasado de nuestras verdades, para mostrarlas como lo que son: elaboraciones ficticias (aunque no falsas), prostéticas, que nos damos como leyes y normas, para con-vivir y ser en común. Este mismo institucionalismo, pensado ahora en términos políticos, se opone a la llamada indivisibilidad de la soberanía (la que necesita del "uno" como principio estructurador de la fuerza y del derecho, bajo las formas del substrato natural, del Dios, del sujeto o de la razón), ${ }^{4}$ para pensar lo múltiple, lo singular-plural, como forma a-principial de un ser-encomún, de un comunismo sucio, mundano, exiliado de las formas mayúsculas de la Historia y la Redención. ${ }^{5}$ Sería precisamente ahí, en la convergencia entre genealogía y anarquía (ambas entendidas como derogación del archēo principio de autoridad) donde mejor se aprecia la relación constitutiva entre historicidad y democracia, la que no puede sino oponerse, permanentemente, a la ficción soberana convertida en dogma, herencia o tradición. ${ }^{6} \mathrm{Y}$ sería

3 Claude Lefort, La invención democrática, 1996.

4 Reiner Schürmann, El principio de anarquía, 2017.

5 Nancy, Ser singular-plural, 2006; Carlos Casanova, Comunismo de los sentidos, 2017.

6 La cuestión de la historia, como relato y reconstrucción, pero también en relación con la cuestión más compleja de la historicidad está en el centro de la problematización de la soberanía. 
ahí mismo donde la ley, el derecho, la Constitución y las instituciones se muestran como prótesis que suplementan la vida colectiva y que pueden ser potencialmente alteradas de acuerdo con las forma de ser en común.

En este sentido, la pregunta del Discurso es, sin necesariamente proponérselo, la pregunta por el poder y su legitimidad, por la ficción de la soberanía, y por los límites de dicha ficción. Y su actualidad deriva de su extraordinaria pertinencia: ¿cómo es posible que los hombres, las mujeres, todos, todas y todes, no se rebelen contra un poder que no se cansa de exponer su falta final de fundamento y su arbitrariedad constitutiva? En efecto, más allá de que el Discurso se ha convertido en un texto importante para varias constelaciones de pensamiento radical, ${ }^{7}$ nos interesa retomar la simpleza abismal de su interrogación para pensar no solo la insubordinación creciente de las sociedades contemporáneas frente a la gobernabilidad neoliberal, sino, y atendiendo al caso chileno, para denunciar las diversas estratagemas de contención y subordinación con las que se pretende seguir manteniendo la servidumbre de la mayoría al servicio de una elite que no se cansa de ejercer una tiranía avalada en la expropiación de la política y del derecho para su propio beneficio.

En última instancia, lo que está en juego con las recientes revueltas, en Chile y en el resto del mundo, pero también con los diversos mecanismos de neutralización y contención empleados por el Estado y los partidos políticos para contener su potencial instituyente, es precisamente el develamiento de

Más allá de la crítica de los usos de la historia (Nietzsche), interesa pensar cómo, aún cuando la cuestión de la historicidad parece estar en el centro de las preocupaciones heideggerianas relativas a la destrucción de la metafísica, en la medida en que dicha destrucción depende todavía de una determinada "historia del ser", sigue presa de una inadvertida complicidad o co-pertenencia ontológica entre soberanía, decisión y auto-referencialidad (el autos de la autarquía). Es esto precisamente lo que Derrida interroga en la destrucción heideggeriana de la metafísica, y lo que le sirve de hilo conductor para interrogar la misma cuestión de la soberanía en el pensamiento contemporáneo. Jacques Derrida, La bestia y el soberano, 2010.

7 Entre las que destaca aquella que va desde Claude Lefort y Cornelius Castoriadis hasta Pierre Clastres y Miguel Abensour, para no mencionar la estrecha relación que la pregunta misma tiene con la llamada "hipótesis represiva", aquella que, desde Wilhelm Reich hasta Michel Foucault, interroga el cómo y el porqué de la complicidad de los hombres con su propia dominación. 
la profunda crisis de autoridad de la gobernabilidad neoliberal; crisis que no por casualidad se expresa como necesidad de un nuevo pacto social. Las revueltas refutan el consentimiento espontáneo de la servidumbre voluntaria, profanan el carácter sagrado del vínculo que la autoridad pretende fundar en la Constitución, dejando abierta la pregunta por la forma misma de un nuevo contrato social, el que más allá de su condición jurídica, debería suponer una relación profana con la ley y su autoridad.

En este ensayo, intentamos una lectura tanto de la crisis de la gobernabilidad neoliberal como de la singularidad de las revueltas chilenas, las que han sido capaces de poner en el centro del debate político nacional la necesidad de una nueva Constitución, más allá de las limitaciones jurídicas e institucionales que configuran en Chile una verdadera cultura juristocrática. Hacia el final de nuestra reflexión, intentamos un comentario crítico de lo que bien podría denominarse "un nuevo constitucionalismo espiritual" que, basado en un "criollismo tardío" y advertido de la "falta" estructural de programa en la administración neoliberal, pretende volver a pensar el sustrato profundo de la ley, recurriendo a una tradición de pensamiento nacional e identitario de carácter hermenéutico-cultural. No intentamos desacreditar ni denunciar ideológicamente dicho "constitucionalismo espiritual", sino confrontarlo reflexivamente, siempre que en este se hacen explícitas las ambivalencias del pensamiento político contemporáneo.

\section{REVUELTAS Y CRISIS}

Con la serie de protestas sociales que comenzaron el mes de octubre del año 2019, Chile ingresó en un proceso de cambio en el que todavía estamos domiciliados. El viernes 18 de octubre, los estudiantes secundarios se manifestaron contra la administración de Sebastián Piñera mediante la evasión del pasaje de metro, gatillando una nefasta reacción del gobierno que, escandalizado ante "tamaña fechoría", decidió sacar el ejército a la calle, declarando un innecesario estado de emergencia que resultó absolutamente contraproducente. La presencia del ejército en la vida cívica rememoraba la 
excepcionalidad del año 2010, cuando la primera administración de Piñera no supo cómo responder a la crisis de abastecimiento generada por el terremoto del 27 de febrero de dicho año, teniendo que recurrir al ejército para frenar los desfalcos masivos de supermercados y proteger la propiedad privada y la seguridad pública (en ese mismo orden de prioridades). A pesar de que este recurso contemplado en la Constitución para situaciones extraordinarias se muestra como una herramienta habitual de las administraciones de derechas en momentos de crisis, La decisión de Piñera no pudo evitar reposicionar, en el golpeado imaginario nacional, la sospecha insuperable de la población civil con respecto a la institución castrense, vinculada con la violación sistemática de los derechos humanos y la suspensión de todas las garantías democráticas durante el régimen dictatorial de Augusto Pinochet.

En menos de una semana, las manifestaciones estudiantiles se habían convertido en una revuelta popular a nivel nacional, articulando el rechazo al alza de los pasajes del metro con el sostenido rechazo a la serie de abusos e injusticias que han caracterizado a la gobernabilidad neoliberal desde su violenta instauración, bajo el régimen dictatorial: desfalco y colusión empresarial para el manejo de precios; corrupción y financiamiento secreto de los partidos políticos; acuerdos palaciegos para frenar procesos de democratización y mantener el sistema electoral anti-democrático; institucionalización del robo y la expoliación gracias a los sistemas de pensiones y de salud vigentes; la "ejemplar" ley de pesca que sanciona un reparto del mar entre los mismos grupos económicos que se han adueñado sistemáticamente del país; la impunidad notoria para los criminales condenados después de la dictadura; el carácter selectivo de la justicia y las diferencias de penas o castigos según el estatus socio-económico de los inculpados; el alza sostenida del costo de la vida gracias una política de impuestos orientada a gravar el consumo y no la riqueza; la precarización constante de las condiciones de trabajo mediante la perpetuación de un código laboral basado en criterios de flexibilidad y subcontratación; el crecimiento sostenido de la deuda privada como mecanismo de contención del descontento social; el fracaso notorio de la "movilidad social" como resultado de un sistema educacional privatizado y orientado al 
lucro; etc. ${ }^{8}$ Todos estos fenómenos pueden ser vistos como los síntomas más evidentes de una crisis sostenida de la gobernabilidad neoliberal que hasta hoy persevera, de espaldas al pueblo, apelando a múltiples mecanismos antidemocráticos. Las revueltas, empero, han dejado claro que la gobernabilidad neoliberal carece de toda compostura y no puede limitar su insaciable apetito, a pesar de que es ella misma la que esta devastando al país, cuestión que expone a sus ideólogos y funcionarios políticos a una pérdida generalizada de legitimidad, acompañada por un cinismo casi criminal que la aleja del viejo proyecto conservador de la derecha histórica chilena. ${ }^{9}$

Esta crisis de gobernabilidad, en efecto, no es solo el resultado de los abusos institucionalizados en el estado de derecho, sino que, más allá de las especificidades del caso nacional, habría que considerar la situación chilena en el contexto de las revueltas sociales que desde comienzos del año 2018 han venido ocurriendo en Medio Oriente, Europa, y en otros países latinoamericanos. En este sentido, no estamos ante lo que los sociólogos suelen llamar una "crisis de legitimidad" acotada al Estado nacional y sus órdenes

8 Más allá de los informes del PNUD y de varios otros organismos nacionales e internacionales, véase esta serie acotada de trabajos informativos: de María Olivia Mönckeberg, El saqueo de los grupos económicos al Estado de Chile, 2015. También de ella, La máquina para defraudar: Los casos Penta y Soquimich, 2015. De Ernesto Carmona Ulloa, Los dueños de Chile, 2002. De Daniel Matamala, Poderoso caballero. El peso del dinero en la política chilena, 2015. Y de Hugo Fazio, Mapa actual de la extrema riqueza en Chile, 1997; y su más reciente volumen, Los mecanismos fraudulentos de hacer fortuna: Mapa de la extrema riqueza, 2015.

9 Este es, por supuesto, el reclamo del mismo Mario Góngora contra la dictadura y su disolución del Estado nacional soberano (Ensayo histórico sobre la noción de estado en Chile, 1986), eje de una tradición conservadora que tiene como horizonte la imbricación soberana entre Estado y nación, territorio e identidad. La desregulación o desmontaje del contrato social nacional ejercido por la instauración, manu militari, del neoliberalismo en tiempos dictatoriales, sería lo que nos permite comprender, a su vez, el pasaje desde el moderno empresario de tipo weberiano (sacrificial y ahorrativo), al nuevo businessman, orientado a la ganancia y la gratificación, y abocado ya no a un proyecto de desarrollo nacional, sino a la ubicua especulación financiera. Entender esta transición en el mismo proceso de acumulación permite comprender el carácter estructural de la llamada corrupción empresarial en Chile, ya no como producto de una falla moral o de carácter, sino como efecto de una liberalización general de la misma acumulación. Véase también el ensayo más comprensivo sobre la crisis de la derecha de Hugo Herrera, La derecha en la crisis del Bicentenario, 2014, que dio paso a un debate acotado, pero que merece ser revisado. 
institucionales, sino que estamos frente a una crisis tendencial y constitutiva de la acumulación capitalista desregulada y flexible, que ya no opera según los criterios de estabilidad que definían el patrón de acumulación vinculado con el predomino del Estado nacional como marco soberano y regulativo de los mercados. En tal caso, la precarización de la vida, la híper-explotación del trabajo y la devastación de los recursos naturales (características del llamado “consenso de las mercancías") $)^{10}$, no son ni fenómenos puntuales o pasajeros, ni se explican por problemas técnicos de implementación o "malas" políticas públicas, sino que responden a la condición axiomática e impredecible de la llamada economía globalizada. Las revueltas chilenas se inscriben entonces en un deterioro progresivo de la gobernabilidad neoliberal que, orientada a la intensificación de los procesos de acumulación, no pareciera tener como límite el viejo horizonte reformista burgués relativo al Estado de derecho. ${ }^{11}$

Tampoco debemos descontextualizar las revueltas inauguradas en octubre del 2019, como si se tratara de un fenómeno puntual o espontáneo, pues estas luchas estudiantiles y populares se inscriben en una serie de reacciones contra la gobernabilidad neoliberal desencadenadas desde fines del siglo pasado, cuestión patente en los diversos ciclos de protestas estudiantiles (desde las movilizaciones contra la "racionalización" implementada por Federici en la Universidad de Chile, el año 1987, hasta las manifestaciones del 2006 denominadas "La revolución de los pingüinos"; incluyendo el masivo movimiento del 2011 y las más cercanas manifestaciones feministas del 2018), y en las jornadas de protestas populares, como aquellas de los años 1982-1986

10 Maristella Svampa, “'Consenso de los Commodities' y lenguajes de valoración en América Latina", 2013.

11 Conclusión a la que llega, entre otros, Thomas Piketty (El capital en el siglo XXI, 2014), a partir de constatar como la brecha salarial, el aumento de las desigualdades sociales, la sostenida pauperización de la población y la tendencia creciente a la concentración de la propiedad y de la riqueza en pocas manos, junto con la mínima movilidad social y la falta creciente de políticas públicas en áreas tales como la educación, la salud, los recursos naturales, etc., nos llevan a indicadores socio-económicos similares a aquellos que, desde fines del siglo XIX y comienzos del XX, derivaron en la emergencia de la llamada cuestión social y, eventualmente, en la revolución y las guerras. Más que progresar, el capitalismo intensifica sus procesos de devastación. 
(que produjeron la crisis del mando dictatorial, para ser luego disciplinadas por la retórica transicional), hasta los levantamientos sectoriales (vivienda, profesores, salud, empelados públicos) y regionales (Calama, Aysén, Lota, Coronel. etc.) de las últimas décadas. En este contexto histórico, podemos comprender las revueltas (chilenas e internacionales) como manifestaciones de una crisis de la gobernabilidad neoliberal producida por la misma intensificación de los procesos de extracción y acumulación que definen al neoliberalismo. La consecuencia fundamental de esta crisis tendencial y constitutiva es el agotamiento del imaginario político y jurídico moderno, cuestión que nos demanda una nueva imaginación instituyente capaz de producir nuevas prótesis institucionales para un mundo cuya complejidad ha desbordado las hormas tradicionales definidas por la arquitectura política moderna (Estado, nación, Constitución, clase, sujeto, representación, ideología, hegemonía, etc.).

A esto se debe, sin duda, el que las diversas protestas y manifestaciones populares de estos últimos años no se agoten ni reduzcan a simples reivindicaciones económicas puntuales o demandas identitarias de reconocimiento. Por el contrario, dado el nivel de frustración social con respecto a las gestiones gubernamentales de los dos bloques de poder que se han turnado en el gobierno durante los últimos treinta años, ${ }^{12}$ estas manifestaciones pueden ser asociadas con un proceso destituyente y radical que tiene como finalidad, paradójicamente, la de darse a sí mismo una nueva Constitución. ${ }^{13}$ En efecto, más allá de la aparente contradicción entre el carácter

12 Por un lado, La Concertación de Partidos por la Democracia, que luego se cambió el nombre a Nueva Mayoría; por otro lado, La alianza por Chile que también se cambió el nombre a Chile vamos. Ambos conglomerados han configurado el llamado duopolio nacional, el que se turna en el poder administrando más o menos la misma agenda social y bajo el mismo marco jurídico y constitucional.

13 En efecto, las revueltas pueden ser leídas como una verdadera irrupción demótica, en el sentido en que Rancière piensa la lógica de la política como forma del desacuerdo y como suspensión del consentimiento espontáneo al poder (El desacuerdo. Filosofía y política, 1996), y, en ese sentido, no como expresiones de una voluntad programática o de clase, al modo de una práctica política organizada estratégicamente (Furio Jesi, Spartakus, 2015), sino como respuestas existenciales ante la amenaza creciente y radical del poder devastador contemporáneo (Giorgio Agamben, "Para una teoría de la potencia destituyente", 2017). 
destituyente de las revueltas y sus aspiraciones a una nueva Constitución, lo que resulta relevante en el caso chileno es el hecho de que la misma posibilidad de una nueva Constitución exige la destitución de un modelo duopólico y juristocrático, consagrado en la Constitución vigente desde 1980, su sistema electoral y su sistema de partidos, los que han resultado cruciales en la prolongación de la administración dictatorial en tiempos de gobierno civil. En otras palabras, haber hecho patente la necesidad, inverosímil y compleja, de una nueva Constitución, ajustada a las condiciones materiales y demográficas efectivas de la sociedad chilena, lejos de ser parte de un reformismo jurídico convencional, representa el horizonte más radical del proceso destituyente en curso, y constituye su objetivo inaplazable. Todo esto, siempre y cuando la lucha por una nueva Constitución no se reduzca a la producción de un nuevo pacto jurídico a cargo de expertos y funcionarios, sino que en ella se exprese la incongruencia constitutiva entre las formas de vida realmente existentes en el territorio y los modelos identitarios e ideológicos que el derecho impone sobre lo social. ${ }^{14}$

En este sentido, más allá de las intenciones, a esta altura nefastas, de la administración de Piñera y de los partidos políticos de gobierno y oposición por desechar el debate constituyente, parece muy poco probable que la discusión sobre esta nueva Constitución pueda aplazarse de manera definitiva, a pesar del manejo oportunista de la actual crisis sanitaria abierta con la propagación del Covid-19 y la obvia instrumentalización de dicha crisis por parte del gobierno, que ha utilizado una retórica inmunitaria para suspender no solo la conformación de los procesos constituyentes necesarios para una

Lo que está en juego en las revueltas, en otras palabras, no se reduce ni a reivindicaciones económicas puntuales ni a reformas políticas, sino que se trata de la destitución de los elementos constitutivos de la dominación contemporánea que amenazan con devastar formas completas de vida.

14 En efecto, no basta con la apelación genérica a la idea de "pueblo" para dar cuenta de la heterogeneidad material de lo social: ¿cómo pensar una Constitución abierta a los derechos de los inmigrantes, de las minorías étnicas y sexuales, etc.?, ¿cómo pensar lo popular más allá de los modelos ideológicos de identidad nacional y su organización hegemónica en torno al Estado? Estas preguntas deberían hacer temblar nuestras nociones de identidad y pertenencia, de comunidad y nación, de política y estrategia. 
nueva Constitución, sino que ha aprovechado la ocasión para desmovilizar a la sociedad civil, desactivar las persistentes protestas sociales, criminalizar la participación ciudadana e imponer un ilegítimo plebiscito (relativo a la necesidad o no del cambio constitucional), plebiscito que ha sido, a su vez, postergado, en nombre del mismo "bienestar" ciudadano. ${ }^{15}$

Efectivamente, los argumentos relativos al virus y su propagación han neutralizado, en los meses de marzo, abril y lo que va de mayo, los procesos políticos de democratización, pero no han cristalizado en una política coherente de gobierno frente a la situación de potencial contagio masivo, pues sin esconder su ambivalencia y oportunismo, la actual administración afirma, por un lado, la prohibición de las manifestaciones políticas, mientras que, por otro lado, llama a restablecer la normalidad del 'desarrollo económico'. Poco podemos esperar de esta falta de política coherente en un país caracterizado por la crudeza de sus inviernos, la precariedad de la infraestructura de salud pública y la negligencia criminal de sus autoridades sectoriales. No obstante, el ciclo de revueltas inaugurado en octubre del 2019 ha dejado claro que la gobernabilidad neoliberal chilena carece no solo de legitimidad, sino de programa e imaginación política, mostrándose como lo que siempre fue, una prolongación civil de la gobernabilidad militar. Ninguno de los bloques constituidos en torno al duopolio electoral tiene realmente algo que ofrecer frente a esta crisis, que lejos de ser una crisis convencional, se muestra como el agotamiento del aparato total del desarrollismo neoliberal contemporáneo. ${ }^{16}$

Es aquí, en este contexto de desarticulación y agotamiento, donde nos

15 Entre las múltiples referencias a la problemática biopolítica abierta por Michel Foucault y la definición del poder como capacidad de hacer vivir, más que de dejar morir, referimos acá el panorámico y esclarecedor trabajo de Roberto Esposito, Inmunitas. Protección y negación de la vida, 2005.

16 El actual debate en torno al posible retiro del $10 \%$ desde los fondos previsionales no solo ha generado una desvergonzada campaña de amedrentamiento, desde el ejecutivo, incluyendo a la derecha en pleno, los empresarios y los administradores de las AFP, los que incluso han mandado cartas amenazantes a sus cotizantes, sino que ha develado la fragilidad del desarrollo chileno. Recordemos solo tres cosas relativas a este sistema: 1) que se impuso durante el gobierno dictatorial y en base a mentiras. 2) Que falla en la actualidad porque perpetua un reparto desigual y genera o intensifica la miseria de los jubilados. 3) Que es esencialmente una estrategia de apropiación de recursos individuales para ser capitalizados corporativamente, 
atrevemos a afirmar que el debate sobre la nueva Constitución constituye el horizonte irrenunciable para una política democrática capaz de articular la convergencia entre la historicidad de las revueltas y la anarquía de la ley, cuestión que hemos referido mediante la apelación a un institucionalismo salvaje que le restituye a todos el poder y la potencia de hacer la ley y de imaginar un mundo mejor. El gobierno lo intuye e intenta neutralizarlo mediante el uso de la fuerza, movilizando el ejército bajo el pretexto del orden y la seguridad, pero orden y seguridad no son categorías neutras, representan la imagen ideológicamente invertida de la destrucción capitalista contemporánea.

\section{JURISTOCRACIA}

La juristocracia es el resultado de la consolidación de una cultura institucional y política, basada en un mecanismo constitucional y jurídico en el que las demandas sociales son neutralizadas y diferidas por una burocracia institucional que no responde a los criterios tradicionales de legitimidad, sino a una lógica auto-referencial de perpetuación. Esta auto-referencialidad de las instituciones termina por subsumir la misma actividad política y convertirla

\footnotetext{
con reparto restringido de beneficios, cuestión que explica porqué las fuerzas armadas y carabineros fueron estratégicamente derivados hacia sistemas más equitativos. Después de todo, el pacto dictatorial y su infinita prolongación post-dictatorial descansa, en última instancia, en la posibilidad de hacer uso efectivo de los aparatos represivos para mantener sus tasas de acumulación y ganancia. El sistema previsional, en este sentido, no es solo el orgullo de José Piñera, sino el fetiche que oculta la verdad del golpe, a saber: la de haber usado el ejército no para extirpar el cáncer marxista - esa fue la excusa-, sino para favorecer un proceso rigurosamente diseñado de reconcentración de la propiedad, el poder y la riqueza, en manos de una elite financiera que, en estos últimos 50 años, no solo se lleva el salario difícilmente ganado de los trabajadores, y no solo lo usa para especular en la bolsa o en los mercados de valores internacionales, sino que ha usado y usa este dinero para financiar y solventar el aparato bancario y especulativo con el que esta misma derecha neoliberal chilena juega a hacerse la liberal y emprendedora, pero con plata ajena. El robo y la negligencia criminal de políticos y empresarios, secundados por la indignidad de todos los uniformados, están inscritos en el corazón de la democracia nacional que no es sino un cerrojo de captura que tiene atrapado a sus ciudadanos en una narrativa que nadie comparte, pero que se sostiene con el poder y la fuerza. No olvidemos que los mismos miembros del gobierno o dl parlamento, se turnan también como miembros de las mesas directivas de las AFP, de las mesas directivas de los bancos y de las mesas directivas de los medios de comunicación y prensa.
} 
en simple administración. Más allá del horizonte weberiano-habermasiano relativo al derecho y al orden burocrático como forma de racionalización y de colonización del mundo de la vida, nos interesa reparar acá en el análisis del constitucionalismo contemporáneo desarrollado por Ran Hirschl, quien, revisando los casos de Canadá, Israel, Nueva Zelanda, Sudáfrica, cuestiona el aparente carácter progresista de la llamada juridización de los derechos sociales; es decir, cuestiona la incorporación de las demandas sociales al interior del marco jurídico constitucional que rige a cada país, precisamente porque dicho 'reconocimiento' jurídico funciona también como dilación de tales demandas. ${ }^{17}$ En este sentido, lo que podría ser perfectamente pensado como un progreso de la ley en términos de derechos sociales, tiende a mostrarse como una forma de contención y de neutralización de las luchas sociales que al ser traducidas al marco jurídico burocrático vigente en cada país, quedan en suspenso, pues el tiempo burocrático del orden institucional y de la Constitución difiere substantivamente del tiempo de la política, entendida como algo más que una mera representación parlamentaria.

Hirschl inscribe su análisis en el horizonte del constitucionalismo desarrollado desde la Segunda Guerra Mundial, caracterizado por un presidencialismo anti-garantista y restrictivo, que terminó por acoplarse flexiblemente con los procesos de liberalización económica, hasta los primeros años del siglo XXI, momento en que una serie de reformas constitucionales y procesos constituyentes debieron ser puestos en práctica, para ajustar los ordenes institucionales tradicionales a las nuevas lógicas abiertas con el proceso de globalización. Sin embargo, dicha globalización, genéricamente descrita como integración económica y socio-cultural, en rigor fue propulsada

17 Toward Juristocracy. The Origins and Consequences of New Constitutionalism, 2004. Tomamos de este trabajo la noción de juristocracia, pero para pensarla en términos más amplios, relativos a la configuración de una cultura institucional y no solo como efecto de una 'constitucionalización' de las demandas sociales. A la vez, la juristocracia no está pensada acá como efecto de una tendencia inherente en la modernidad occidental hacia la racionalización (propia del horizonte weberiano-habermasiano), sino como efecto de un diseño político programático, relativo a las metamorfosis históricas de la soberanía. 
por una serie de procesos históricos bastante complejos, partiendo por la cancelación de los Acuerdos de Bretton Woods, y la liberalización del dólar, hasta la serie de transiciones de los años 1990 que comenzaron con la caída del mundo socialista y los procesos de democratización y pacificación en Europa del Este y América Latina.

En este contexto, la pacificación de las guerras civiles en Centroamérica y las transiciones a la democracia en el Cono Sur, fueron posibles gracias, en cierta medida, a la firma de un nuevo pacto social sobre las ruinas del anterior, destruido por la violencia militar. Esa fue la función de los Informes de Derechos Humanos en la región, pues su promesa de justicia y esclarecimiento permitió, al menos a nivel simbólico, realizar el duelo por las pérdidas y abrirse a la posibilidad de elaborar un nuevo pacto social. Los límites irremediables de estos Informes, la incapacidad institucional para cumplir las demandas de justicia y reparación (en lo que se dio en llamar "democracias tuteladas"), la persistencia de grupos de poder capaces de evitar el nuevo marco jurídico y las mismas demandas provenientes de los procesos de acumulación intensificados por el neoliberalismo, eufóricamente abrazado por la mayoría de los gobiernos regionales hacia fines del siglo XX, determinó en muchos casos, la emergencia de procesos de movilización social que terminaron en la elaboración de nuevas constituciones (Venezuela, Colombia, Ecuador, Bolivia, etc.) y en la configuración de una serie de gobiernos auto-declarados como post-neoliberales, asociados con la llamada Marea Rosada latinoamericana. La mayoría de estos nuevos gobiernos fueron, sin embargo, recientemente desplazados por una re-articulación de la derecha latinoamericana, la que ahora complementa las intensificadas demandas del neoliberalismo con una retórica identitaria y ultra-conservadora, irracional e incluso salvífica. ${ }^{18}$

En Chile, por otro lado, la "reconfiguración" de una cultura juristocrática

18 En efecto, si la gobernabilidad neoliberal, siempre más preocupada de la desregulación y de la flexibilidad de los procesos de acumulación, parece carecer de una propuesta substantiva de sociedad, estas nuevas derechas se muestran como ultra-neoliberales en lo económico, pero recuperan una agenda valórica relativa a un integrismo moral que se centra, otra vez, en la familia hetero-patriarcal, la identidad cultural y nacional y la mediación comunitaria y religiosa como esenciales contra un mundo desterritorializado que es presentado como 
ya en los años 1980, permitió no solo la perpetuación de la Constitución instaurada dicho año, sino que también hizo posible el aplazamiento infinito de las demandas de justicia, mientras los gobiernos de turno coincidían en profundizar el neoliberalismo. ${ }^{19}$ Para entender el alcance y la profundidad de la cultura política e institucional juristocrática chilena debemos atender a los procesos históricos que definen su actualidad, desde el golpe como interrupción del gobierno de Salvador Allende, el último gobierno perteneciente a la historia y al proyecto del Estado nacional y sus esfuerzos de realización; pasando por la brutal implementación del neoliberalismo, en los años inmediatamente posteriores al golpe, incluyendo la imposición fraudulenta de la Constitución de 1980; hasta la expropiación de la agencia política democrática de los movimientos sociales anti-dictatoriales (los que durante los años 1980s habían logrado producir una crisis en el mando dictatorial), expropiación llevada a cabo por la reconfiguración del sistema de partidos políticos, regulados por la constitución del 80 y su ley electoral, desde el año 1986 en adelante. De todo esto resultó una transición pactada a la democracia que dejó fuera de las negociaciones a la sociedad civil, articulada a la nueva política chilena mediante el mecanismo de la promesa y del reparto.

En efecto, la juristocracia chilena está marcada por una tradición constitucionalista fuerte, brutalmente derogada y reconstituida en el régimen militar. Por supuesto, no podemos desplegar acá el argumento en su totalidad, ${ }^{20}$ pero es posible afirmar que el golpe cancela la historia republicana nacional, permite la implementación del neoliberalismo bajo condiciones dictatoriales,

caótico y sin sentido. Las retóricas de Donald Trump y Jair Bolsonaro son ejemplares, aunque el avance de grupos religiosos protestantes, junto a la misma orientación conservadora de la Iglesia Católica (como reacción a la Teología de la liberación), se han hecho sentir en América Latina desde mucho antes.

19 Pensada en el largo plazo histórico, la juristocracia chilena no responde solo a su eventual refundación bajo dictadura, sino que compete a la totalidad de la historia moderna del país, al menos, desde la constitución del llamado orden portaliano, que marcó los límites de la política oficial desde el siglo XIX y que pesa, tan fuertemente, en el imaginario restaurador de Góngora y del nuevo constitucionalismo chileno.

20 Permítasenos referir acá Soberanías en suspenso. Imaginación y violencia en América Latina, 2013. 
lo que implica, a su vez, que la dictadura no tuvo solo una función represiva relativa al containment del comunismo, sino una dimensión productiva, relativa al rediseño de la sociedad chilena, nunca más conciliable con su "supuesta" tradición republicana. ${ }^{21}$ En última instancia, el golpe y el rediseño que le acompañó, trajo consigo una nueva concentración del poder, de la riqueza y de la propiedad en una nueva clase o sector dominante que ya no respondía a la clase dominante tradicional, en sus versiones mercantilistas o latifundistas. Este nuevo sector dominante, él mismo desterritorializado y ajeno a los criterios distintivos de la hegemonía tradicional, inscrita en el marco del Estado nacional, fue capaz de protegerse no solo manu militari, sino mediante mecanismos persuasivos y juristocráticos que han permitido la reproducción del modelo, sin grandes alteraciones, durante los treinta años posteriores al régimen dictatorial.

La constitución de 1980, su trasfondo patrimonialista y retardatario, las premisas políticas y técnicas para la reforma electoral, la misma configuración del sistema de partidos políticos y del sistema electoral ampliado, basado en un criterio de proporcionalidad anti-democrático (que niega, en el fondo, la voluntad popular); sistema que termina por fomentar la formación de un duopolio en torno al poder delEstado, son, más allá de las prácticas de corrupción y de financiamiento ilegal de la política, las instancias distintivas de la trampa soberana o juristocrática nacional. De ahí entonces que la propuesta de cambio constitucional levantada por las revueltas nacionales no sea bien recibida ni por los partidos en el gobierno ni por aquellos que ocupan, al menos simbólicamente, el lugar de la oposición. Cualquier cambio a este sistema juristocrático pone en cuestión lógicas clientelares ya naturalizadas, altera el reparto acotado del poder y afecta el equilibrio entre los grupos económicos dueños de Chile y un sistema político que se da, como función prioritaria, la intensificación del modelo económico, la neutralización de las luchas y revueltas sociales y la protección de los procesos de acumulación de una elite que no puede ser confundida con la representación moderna de las burguesías nacionales.

21 Véase Renato Cristi y Pablo Ruiz-Tagle, La república en Chile, 2007. 
El análisis de la constitución de 1980 elaborado por Renato Cristi y Pablo Ruiz Tagle, junto a la caracterización de la agenda ideológica de su forjador, Jaime Guzmán, son bastante claros al respecto. ${ }^{22}$ Pero la verdadera herencia dictatorial no está solo en el modelo económico ni en la Constitución, sino en la transformación radical de la práctica política, la que, bajo el duopolio, aparece monopolizada por partidos burocratizados que no pueden sino cumplir el temprano (1911) vaticinio de Robert Michels relativo a 'la ley de hierro de la oligarquía', es decir, a la tendencia inevitable de los partidos políticos electorales a constituir una cultura oligárquica interna y de espaldas a la sociedad civil, en el contexto de las democracias liberales occidentales. ${ }^{23}$

Es esto lo que explica la conducta aparentemente negligente de la oposición y la falta de voluntad política para apoyar las recientes revueltas sociales, complicitando con el secuestro institucional de la política y con su reclusión a las instancias de una democracia subsumida a los imperativos del capital. A esto mismo se debe, por supuesto, la generalizada criminalización de las prácticas democráticas, asambleístas y constituyentes por parte de un establishment comprometido con la gobernabilidad neoliberal, y el consecuente avance de iniciativas de pacificación a espaldas del pueblo. $\mathrm{Y}$ es precisamente en este contexto donde habría que leer la continuidad histórica entre el famoso "Acuerdo Nacional para la Transición a la Plena Democracia", firmado por 11 partidos políticos de oposición al régimen de Pinochet, el 25 de agosto de 1985, acuerdo que dio paso a la infinita transición pactada, y que terminó por desactivar las revueltas populares de ese entonces, inscribiendo su intempestiva temporalidad en el tiempo burocrático de los acuerdos y las transacciones oficiales, y el reciente (y rimbombante) "Gran acuerdo nacional para la paz social y una nueva constitución”, firmado otra vez a espaldas de los movimientos sociales, por un congreso que sesionó en pleno durante la noche del 15 de noviembre del 2019, y que luego se presentó como fin de las revueltas y triunfo de la democracia chilena.

22 Véase de Renato Cristi, El pensamiento político de Jaime Guzmán, 2011.

23 Political Parties, 1962. 
De todas maneras, esta caracterización de la juristocracia nacional no estaría completa sino consideráramos el rol fundamental que cumplieron las ciencias sociales en esta revolución neoliberal. Tanto la economía, que pretenciosamente se auto-definió como "ingeniería comercial", como la sociología, que abandonando sus agendas críticas del pasado, adquirió nuevas credenciales públicas (después de la censura dictatorial) a partir de convertir sus categorías hermenéuticas en conceptos agrupados por una teleología menor relativa a la transición democrática nacional. El papel de la economía y su funcionalización neoliberal ha sido bastante estudiado, aunque eso no afecte en lo más mínimo el credo cotidiano de las elites políticas, educacionales y económicas de Chile. El papel de la sociología convertida en transitología todavía merece, sobre todo ahora, una nueva mención.

En efecto, si el pensamiento social clásico comprendía la forma en que los hombres, fruto de su vida colectiva, eran capaces de otorgarse leyes para ir regulando su propia convivencia. Esa comprensión le permitía pensar la lógica de la política como una lógica capaz de auto-instituir un orden, respecto del cual, las normas y leyes que los hombres se daban, no eran sino el producto de un momento instituyente, momento artificioso que no hace sino suplementar las lógicas del poder con la proposición prostética de una segunda naturaleza, una naturaleza artificial pero no falsa, en la que descansa un contrato social tácito, ya mucho antes de la ley y de la constitución. ${ }^{24}$ De una u otra forma, ese pensamiento social compartía con el institucionalismo salvaje la idea de que las leyes son inventos o artificios que los hombres se dan para contrarrestar el hecho de haber sido abandonados por Dios. En la ausencia de una causa primera, de un principio regulativo o de un telos definitivo, los hombres habitan el mundo, anárquicamente, pero esa anarquía nada tiene que ver con las caricaturas conservadoras sobre el anarquismo histórico, pues se refiere a la falta de archē como condición de posibilidad para la misma invención

24 Véase acá, por ejemplo, la lectura que Deleuze realiza de Hume y su contractualismo asociativo. Pure Immanence, 2001. Y la lectura que Émile Durkheim realiza de Hobbes, Hobbes entre líneas, 2014 (texto que recoge las notas de clases recogidas por su sobrino, Marcel Mauss). 
democrática, como afirmaba el ya mencionado Claude Lefort (La invención democrática).

Pero, ¿porqué nos interesa esto?, porque lo que este pensamiento social propone no es sino la posibilidad auto-instituyente como posibilidad de darse, de manera inmanente o indeterminada, un orden social. Frente al fárrago de los acontecimientos, frente a la "anarquía" de las fuerzas, este institucionalismo salvaje postula una normatividad emergida no desde la voluntad individual y "racional" de cada uno, sino del común de la vida colectiva, esto es, desde una éticidad inter-subjetiva, para tomar esta cara noción hegeliana, que antecede, en su constitución común, a la misma narrativa genética, individualista y racional del derecho moderno. En vez de pensar esto, las sociologías transitológicas, se abocaron a pensar las claves normativas de un nuevo orden gubernamental (Tironi, Garretón), cuando no, simplemente a darle la bienvenida a una esquiva modernidad neoliberal (Brunner). En efecto, estas transitologías complementaron la herencia juristocrática de la dictadura al preferir pensar las claves institucionales del pacto transicional en vez de abocarse al proceso instituyente que el fin de la dictadura prometía y que sigue pendiente, respirando en el corazón de las revueltas sociales. A su vez, incapaces de pensar la historicidad de estas revueltas, las sociologías transitológicas volvieron a poner de moda el arsenal de una secreta criminología social, para la que el carácter de la multitud, la irracionalidad de los reventones históricos, o la anomia de las prácticas sociales eran evidentes, pues permitían confirmar teórica y "científicamente" la misma criminalización inmunitaria del pueblo, llevada a cabo, históricamente, por lo diversos actores institucionales que han configurado la anatomía del duopolio chileno.

\section{REPUBLICANISMO PLEBEYO}

Considerando todos estos elementos, procedemos ahora a concluir nuestra intervención de manera programática, reiterando que la potencia destituyente expresada por las revueltas sociales chilenas ha llegado felizmente a formular, como reivindicación central, la necesidad de una 
nueva Constitución. Lejos de reducir esta demanda a una nueva estrategia juristocrática o de conformarnos con un reformismo jurídico que intenta solo cambiar el instrumento de la dominación, sostenemos que el debate en torno al actual proceso constituyente fue inaugurado no por la buena voluntad del gobierno ni por el llamado de los partidos políticos de oposición, sino por la decisión de insubordinación que define a los participantes de las revueltas. $\mathrm{Y}$ es esta insubordinación la que marca el tiempo de una política libre de las amarras juristocráticas que siguen limitando la "ejemplar" democracia chilena. Pero, pensar el estatuto de esta nueva Constitución requiere no solo desmarcarnos de la juristocracia chilena y sus modalidades institucionales y transitológicas, sino también cuestionar los límites del derecho constitucional contemporáneo, desde una concepción salvaje de las instituciones y anárquica de la democracia.

La primera condición para una discusión propiamente democrática en torno al proceso constituyente es la renuncia a los lenguajes técnicos y a la auto-asignada autoridad de los expertos, en relación con el proceso jurídico e institucional relativo tanto a la Asamblea Constituyente, los plebiscitos que la acompañan, la redacción de la Constitución, como al sistema electoral utilizado para la elección de los delegados a dicha Asamblea y, por supuesto, el proceso relativo a su proclamación definitiva. Sin embargo, este cuestionamiento del carácter restrictivo de los lenguajes jurídicos y técnicos no solo apunta a la cuestión formal de los procesos técnicos, sino al mismo estatuto del derecho en las sociedades tardo-capitalistas. En otras palabras, el cuestionamiento de los criterios jurídicos y burocráticos del derecho constitucional no se reduce a una simple observación sobre el carácter restrictivo de sus nomenclaturas, sino que apunta a la misma cuestión de las pretensiones hermenéuticas de verdad histórica que sindican a los juristas como intelectuales referenciales y a la Constitución como encarnación final del espíritu de los pueblos. Se trata de cuestionar tanto el fundamento jurídico de la Constitución, entendido como resultado lógico de un debate "racional", "verdadero" e, incluso, "científico", sin dejar de cuestionar, a la misma vez, el auto-posicionamiento de los juristas y expertos como vanguardia del proceso instituyente. Lo que las revueltas han 
dejado claro es que nadie emancipa a nadie y que toda pretensión vanguardista restituye las dinámicas de la diferenciación y de la experticia. Contra ellas, solo cabe apelar a lo que Jacques Rancière ha llamado un comunismo de las inteligencias, para el que la igualdad no es el resultado sino la condición misma de la política. ${ }^{25}$

En este sentido, es necesario atender al límite del derecho constitucional y del constitucionalismo contemporáneo, en cualquiera de sus modalidades. Se trata de cuestionar su "incapacidad" para pensar la forma-ley y la operación efectiva del derecho, la que descansa en un principio de optimización de la vida $\mathrm{y}$ del orden, y en un presupuesto evolucionista o historicista de comprensión que lo abastece y lo dinamiza. En tal caso, la crítica del derecho debe atender a 1) los presupuestos ontológicos del fundamento normativo con el que se realiza el diseño de sociedad implícito en el marco constitucional. 2) Los presupuestos antropológicos de su concepción subjetiva del orden y de la acción con arreglo a normas, pues la ontología jurídica del orden supone una antropología filosófica suplementaria, una determinada imagen del hombre y de la sociedad en la que se sigue expresando la sobredeterminación utilitaria y maximizadora (el criterio de costo versus beneficios) que caracterizó al primer liberalismo, agudizada ahora por la masificación del presupuesto neoliberal del homo economicus. 3) Los presupuestos procedimentales de su puesta en escena como Constitución y como derecho. La crítica de la onto-teología del derecho incluye la crítica de su antropología filosófica (relativa al humanismo, al patriarcalismo y al especismo) y la crítica de sus instanciaciones efectivas (democracias liberales). De esta manera, un cuestionamiento de la forma-ley y de la operación efectiva del derecho implica también un cuestionamiento de la auto-comprensión de las democracias liberales como resultado lógico y óptimo de la historia (del fin de la historia). Pensar la condición an-árquica de la "ontología" jurídica, supone también pensar más allá del principio subjetivo estructurante del derecho y de la política, abriendo la posibilidad de un nuevo pensamiento de la democracia por venir, de la democracia que no ha

25 “Communism without Communism?”, 2010. 
tenido lugar, más allá de las nociones catedralicias de pertenencia, autoctonía, ciudadanía e identidad nacional.

En efecto, instalar el debate en este horizonte nos permite, paralelamente, entender el derecho como una ficción que olvida su origen hipotético y que oculta dicho origen en una operación reconstructiva que pasa por distanciarse a sí mismo (demarcación) de la ficción y la especulación, de la literatura y de la filosofía, mientras que le delega a la filosofía el campo de la especulación y a la literatura el campo de la ficción. Por el contrario, la misma Constitución debe ser evidenciada como una novela que olvida su condición ficcional, pretendiendo ser la encarnación de un orden histórico del Ser o de una disposición transcendental de la naturaleza humana. En otras palabras, la novela, al igual que la Constitución, está tramada por la postulación de una posibilidad de vida en común, cuya regulación es inmanente a sí misma, y no viene dada por ninguna autoridad transhistórica. El llamado comunismo profano o sucio del que hemos hablado antes, reposa entonces en la condición salvaje de un constitucionalismo novelado, ficcional, que no reconoce dioses ni criterios trascendentales y que el derecho se encarga siempre de denunciar, mostrando la ficción literaria como impura y contaminada: ficción e imaginación manchadas por un deseo irracional, por un averroísmo soterrado. El derecho emprende así una lucha monoteísta contra la multiplicidad de las potencias, denunciándolas en su no saber, restituyéndolas al esquema archeoteleológico de la deuda y de la culpa.

A su vez, y para darle a este horizonte un cierto aterrizaje en nuestra situación actual, sostenemos que es aquí donde cabría preguntarse por los debates internos al constitucionalismo latinoamericano contemporáneo. Dicho esquemáticamente, este constitucionalismo está dividido entre 1) los defensores de una "necesidad constituyente" que empoderando al ejecutivo, le dan atribuciones correctivas para, dentro de la Constitución, acabar con las evidentes injusticias sociales (se suele identificar los casos de Ecuador, Bolivia y Venezuela con este tipo de constitucionalismo) y se suele contraargumentar que dichas atribuciones terminarían por arruinar el mismo marco institucional, haciéndolo derivar en un caudillismo de nuevo tipo, o en un 
populismo constitucional y descarado. ${ }^{26} \mathrm{Y}$, 2) el constitucionalismo liberal, que se sometería a la lógica representativa, limitando al ejecutivo y respetando a las minorías, manteniendo siempre la pureza del fundamento jurídico sin contaminarla con demandas sociales (un constitucionalismo surgido de la apropiación neoconservadora de Hannah Arendt, por ejemplo, o el llamado constitucionalismo procedimental). Un caso extremo de este último tipo sería el llamado constitucionalismo del miedo, ${ }^{27}$ cuyo ejemplo central sería la Constitución chilena de 1980, surgida como reacción a la Reforma Agraria entendida como afrenta y derogación del derecho "fundamental" a la propiedad privada.

En este contexto, los defensores de la Constitución chilena de 1980 ya no tienen mucho margen de argumentación, en la medida en que la tendencia general del constitucionalismo contemporáneo se debate entre aquellos que afirman la fuerza constituyente delegada en el poder ejecutivo (un presidencialismo fuerte, pero regulado por asambleas constituyentes periódicas), y un constitucionalismo liberal-democrático, tensado por la actual e innegable crisis de legitimación y por la necesidad de hacer coherente el marco constitucional con el desarrollo del derecho internacional, ${ }^{28}$ y superar la corrupción estructural que se sigue de la llamada "reproducción de las elites". De hecho, el análisis crítico de la Constitución de 1980 y de sus fundamentos ideológicos y doctrinarios, entre Opus Dei y neoliberalismo à la Friedman, en la constitución del Estado subsidiario chileno, ${ }^{29}$ deja claro el carácter autoproclamado, ilegítimo y anti-democrático de dicha Constitución, la que solo se sostiene por la fuerza y el pacto juristocrático del establishment, al que hay que agregar el monopolio criminal de los medios de comunicación en manos de los grupos económicos dominantes en el país, y su respectivo papel

26 Véase Viciano y Martínez Dalmau, “Se puede hablar de un Nuevo Constitucionalismo Latinoamericano como corriente doctrinal sistematizada?", 2010.

27 Cristi, Ruiz-Tagle, El constitucionalismo del miedo, 2014.

28 Roberto Gargarella, La sala de máquinas de la Constitución, 2015.

29 Los ya citados Cristi y Ruiz Tagle, La república en Chile, 2006; y, Cristi, El pensamiento político de Jaime Guzmán, 2011. 
performativo en el diseño de los debates políticos y públicos.

Por supuesto, el consenso, más o menos establecido, más o menos tácito, respecto al carácter anacrónico e ilegítimo de la Constitución de 1980, recién abre el debate, y es ahí, en este "nuevo" debate, donde habría que entender cómo una parte de la derecha, atemorizada por el constitucionalismo constituyente, intenta pensar esta nueva Constitución según una hermenéutica cultural definida por valores históricamente constituidos en la tradición del pensamiento nacional. Esta forma de criollismo tardio intenta pensar la Constitución como arte de la comprensión del espíritu profundo de un Pueblo, entendiendo al Pueblo de manera substancial y ontológicamente especificable. Es en este ámbito donde habría que disputarle el terreno al constitucionalismo espiritual chileno, que busca en la tradición del ensayismo de vocación estatal (desde Francisco Antonio Encina hasta Mario Góngora, pasando por los Edwards) y en el ejemplo fetichizado de la Constitución de 1925, una alternativa a la Constitución de 1980, la que para esta misma derecha sensata, habría perdido toda posibilidad en la medida en que su absoluta falta de legitimidad se hace cada vez más evidente. ${ }^{30}$ En este sentido, el recambio interino al constitucionalismo de derecha pasa por una recuperación de la legitimidad jurídica y política que apela a la vinculación entre Pueblo (mestizo y criollo) y Territorio, es decir, pasa por una modulación de la soberanía como horizonte irrenunciable de la política, y de la política como una práctica hermenéutica de interpretación de las profundas pulsiones del Pueblo (y del carácter nacional). No se trata, como se ve, de un constitucionalismo reaccionario o simplemente conservador, sino de una hermenéutica cultural y substancialista que restituye una topología logocéntrica que le asigna a la política la tarea de interpretación de la historia, pero de una historia entendida onto-teológicamente, como despliegue de una cierta identidad cultural y como destino de la nación. ${ }^{31}$

Es esto lo que hay que confrontar, el alma bella que, entretenida con el

30 Arturo Fontaine, Hugo E. Herrera, et al., 1925, Continuidad republicana y legitimidad constitucional: una propuesta, 2018.

31 Hugo E. Herrera, Octubre en Chile. Acontecimiento y comprensión política: hacia un republicanismo popular, 2019. 
paisajismo descriptivo y psicologizante del ensayismo conservador, redescubre el fundamento de la ley en el espíritu de un pueblo constituido por la singularidad histórica de su propia formación mestiza. Este criollismo tardio también ha caracterizado a las estrategias hegemónicas de la izquierda contemporánea, la que, sin poder pensar en la historicidad misma de las revueltas, las devuelve a la lógica de articulación de las diferencias, a la configuración de un bloque popular contra el poder, y a la sutura de sus diferencias en la configuración molar de una identidad nacional y popular. Todos terminan en el mismo lugar: nacionales y populares, hijos menores de un hegelianismo de derecha.

De todo lo anterior se sigue entonces la necesidad de insistir en lo siguiente: de no mediar una crítica de los mojones teológico-jurídicos y espirituales que abastecen el debate jurídico constitucional chileno, el constitucionalismo chileno terminará cumpliendo la función que históricamente ha cumplido y que comparte con los discursos sociológicos de la transición, es decir, terminará por favorecer un secuestro juristocrático de la democracia, aludiendo a la necesidad del equilibrio y de la gobernabilidad, sin reparar en que esa gobernabilidad remite a la aporética constitución del derecho moderno, que consiste en la división de los derechos políticos y los derechos privados (como decía Marx, los derechos del hombre abstracto). ${ }^{32}$

Casi nunca en la historia, ni en América Latina ni en Chile, hemos tenido la posibilidad de un verdadero debate constituyente, de una práctica mediada por una asamblea constituyente y efectiva, sino que, por el contrario, la corta pero abundante historia constitucional del país y del continente, muestra claramente como los diseños constitucionales implementados una y otra vez han sido desarrollados desde la imposición de los criterios de una elite criolla, que se turna entre un polo libre-cambista y un polo ultramontano, católico y quasi-monárquico. $\mathrm{Ni}$ el federalismo ni el republicanismo han sido posibles sin ser inmediatamente subsumidos a las dinámicas librecambistas y patrimonialistas de una clase dominante que entiende el derecho, la política y la misma Constitución, como herramientas al servicio de su dominación.

32 Karl Marx, La cuestión judia, 1992. 
Frente a este esquema juristocrático, ya sea que hablemos de los defensores de la Constitución de 1980 o de la derecha espiritual que quiere volver a la Constitución de 1925, o que sigue pensando la Constitución como emanación del espíritu del Pueblo (tal y como este Pueblo aparece en el ensayismo de factura gongorina), habría que oponer las potencias imaginativas de la ficción. Es decir, frente al ensayo de orientación estatal, habría que pensar en una cierta literatura menor como puesta en escena de los pueblos bárbaros y sus vidas mínimas. En efecto, no se trata de oponer al ensayismo identitario una hermenéutica literaria (pues ese fue el proyecto fundacional de la república criolla latinoamericana), sino de mostrar la ficción literaria como subversión de toda hermenéutica espiritual: leer dicha novelística menor en la potencialidad de su imaginación profana implica no solo abrirse a la política imaginal de lo literario, sino a la condición ficcional del derecho. Nada de romanticismo entonces, sino la simple constatación de una imaginación monstruosa que podemos percibir, a simple vista, desde José Santos Gonzáles Vera hasta Manuel Rojas, desde Carlos Droguett, hasta las andanzas del Cristo del Elqui, o la novelística reciente de Diamela Eltit y las crónicas de Pedro Lemebel. Se trata de la puesta en escena de un pueblo mínimo, heteróclito, irrepresentable e irreducible a una imagen única y coherente. Esto, por supuesto demanda otra relación con la literatura, más allá de su subordinación a los procesos de formación nacional, su reducción a la condición de alegoría identitaria o su instrumentalización pedagógica por parte del Estado, se trata de abrirse a una literatura menor y profana para la que no hay ni nunca hubo "un pueblo", ni menos "el Pueblo", sino una hidra de muchas cabezas, un monstruo intempestivo, pasajero, múltiple. ${ }^{33}$

Estas son, finalmente, solo algunas de las dimensiones relevantes que hay que mantener presentes a la hora de pensar en un proceso constituyente. Por de pronto, lo más importante es insistir en la necesidad de una asamblea representativa, democrática y abierta, es decir, de una verdadera asamblea

33 Véase de Eliseo Lara Órdenes, Narradores y anarquistas, 2014. Georges Didi-Huberman, Pueblos expuestos, pueblos figurantes, 2014. 
constituyente, para hacer frente a las medidas e intensiones limitativas del gobierno y de la oposición con respecto a la posibilidad de un nuevo acuerdo constitucional en el país. Pero, en forma paralela a esta lucha concreta, hay que anticipar el debate con la derecha espiritual que propone una Constitución basada en las particularidades del carácter nacional. Lo que resulta ralamente peligroso de este desplazamiento es que, como tal, solo puede existir al interior de la derecha porque la crisis de la gobernabilidad neoliberal se hace cada vez más indesmentible. En efecto, el neoliberalismo no tiene una propuesta nacional, no le compete entreverarse con una referencialidad nómica adscrita al patrón de acumulación previo, es, como fuerza desterritorializadora, un permanente proceso de abrogación de la soberanía nacional en función de favorecer la soberanía del capital. Sería precisamente esa carencia de "política pública" efectiva, que constituye uno de sus aspectos distintivos, lo que ahora, en plena crisis, se muestra como un defecto mayor, si asumimos que la crisis de gobernabilidad abierta con las protestas implica, precisamente, un quiebre de la débil interpelación neoliberal y sus promesas. ¿Cómo salir de este entuerto? Para la derecha espiritual, la salida radica en la recuperación no solo del modelo constitucional del 1925, como ya señalamos, sino en la restitución del vínculo hermenéutico entre el pueblo y la ley, cuestión que supone, de acuerdo con el inteligente ensayo de Herrera (El octubre chileno), recuperar lo mejor del ensayismo nacional abocado a pensar la psicología del roto, pues en esa tradición se hayan las claves para recuperar un proyecto de nación en tiempos de globalización y crisis.

Contra esta recaída en el horizonte pre-hegeliano de la ley como encarnación romántica del espíritu del pueblo, pero también contra las lógicas del management neoliberal, el debate político debe atender al carácter profano de un institucionalismo salvaje que está basado en la condición inminente e inmanente de la revuelta, y no en la encarnación de una voluntad soberana o de una estrategia programática emanada desde una política identitaria (de clases, de géneros o cualquier otra). Se trata de pensar la condición múltiple y heterogénea, sucia y profana, de un comunismo que remite al pueblo no como substancia sino como acontecimiento: como el acontecimiento de la libertad 
en cuanto capacidad de auto-institución que desborda, dada sus mismas condiciones históricas y materiales, las lógicas de la interpelación y de la articulaciónhegemónica inscritas en la promesa incierta e infinitamente aplazada del Estado nacional. Ni populismo ni espiritualismo, el institucionalismo salvaje es una suspensión de la transferencia, una cancelación de la deuda, una desarticulación de su trampa juristocrática, una insubordinación, como decíamos, de la servidumbre voluntaria, que no está relacionada con un gran evento en el porvenir, sino con los eventos mínimos y cotidianos de aquellos que ocupando las calles deciden habitar el mundo según relaciones que están más allá de la ley, des-inscribiéndose y de-sujetándose del mandato de la autoridad, practicando una anarquía de lo sentidos orientada al comunismo sucio de un mundo fraternal que está en ciernes en la inmundicia actual. ${ }^{34}$

\section{REFERENCIAS}

Agamben, Giorgio. "Para una teoría de la potencia destituyente". El uso de los cuerpos. Buenos Aires: Adriana Hidalgo Editores, 2017. 469-495.

Boétie, Étienne de la. Discurso sobre la servidumbre voluntaria. Buenos Aires: Terramar, 2008.

Carmona Ulloa, Ernesto. Los dueños de Chile. Santiago: La Huella, 2002.

Casanova, Carlos. Comunismo de los sentidos. Viña del Mar: Catálogo, 2017.

Cristi, Renato y Pablo Ruiz-Tagle. La república en Chile. Teoría y práctica del constitucionalismo republicano. Santiago: LOM, 2007.

El constitucionalismo del miedo. Santiago: LOM, 2014.

Cristi, Renato. El pensamiento político de Jaime Guzmán. Una biografía intelectual. Santiago: LOM, 2011.

Deleuze, Gilles. Pure Immanence. Essays on a Life. New York: Zone Books, 2001.

Derrida, Jacques. Politicas de la amistad. Madrid: Trotta, 1998.

34 Más allá de la habitual referencia a Políticas de la amistad (1998) de Jacques Derrida, véase también de Antoni Domènech, El eclipse de la fraternidad. Una revisión republicana de la tradición socialista, 2000. 
La bestia y el soberano, Vol. 1. Buenos Aires: Manantial, 2010.

Didi-Huberman, Georges. Pueblos expuestos, pueblos figurantes. Buenos Aires: Manantial, 2014.

Domènech, Antoni. El eclipse de la fraternidad. Una revisión republicana de la tradición socialista. Madrid: AKAL, 2000.

Durkheim, Émile. Hobbes entre líneas. Buenos Aires: Interzona, 2014.

Esposito, Roberto. Inmunitas. Protección y negación de la vida. Buenos Aires: Amorrortu, 2005.

Fazio, Hugo. Mapa actual de la extrema riqueza en Chile. Santiago: LOM, 1997.

Los mecanismos fraudulentos de hacer fortuna: Mapa de la extrema riqueza. Santiago: LOM, 2015.

Fontaine, Arturo, Hugo E. Herrera, et al. 1925, Continuidad republicana y legitimidad constitucional: una propuesta. Santiago: Catalonia, 2018.

Gargarella, Roberto. La sala de máquinas de la Constitución. Dos siglos de constitucionalismo en América Latina (1810-2010). Zaragoza: Katz Editores, 2015.

Góngora, Mario. Ensayo histórico sobre la noción de estado en Chile en los siglos XIX y XX. Santiago: Editorial Universitaria, 1986.

Herrera, Hugo. La derecha en la crisis del Bicentenario. Santiago: Universidad Diego Portales, 2014.

Octubre en Chile. Acontecimiento y comprensión politica: hacia un republicanismo popular. Santiago: Editorial Katankura, 2019.

Hirschl, Ran. Toward Juristocracy. The Origins and Consequences of New Constitutionalism. Cambridge, Massachusetts: Harvard University Press, 2004.

Jesi, Furio. Spartakus. Simbología de la revuelta. Buenos Aires: Adriana Hidalgo Editores, 2015.

Kafka, Franz. "Ante la ley". Obras completas, vol. IV. Barcelona; Edicomunicaciones, 1999. 1131-1133.

Lara Órdenes, Eliseo. Narradores y anarquistas. Estética y política en la narrativa del siglo XX. Concepción: Escaparate, 2014. 
Lefort, Claude. La invención democrática. Buenos Aires; Nueva Visión, 1996. Marx, Karl. La cuestión judía y otros escritos. Buenos Aires: Planeta Agostini, 1992.

Matamala, Daniel. Poderoso caballero. El peso del dinero en la política chilena. Santiago: Catalonia, 2015.

Michels, Robert. Political Parties. A Sociological Study of the Oligarchical Tendencies of Modern Democracies. New York: Free Press, 1962.

Mönckeberg, María Olivia. El saqueo de los grupos económicos al Estado de Chile. Madrid: Penguin Random House, 2015.

La máquina para defraudar: Los casos Penta y Soquimich. Madrid: Penguin Random House, 2015.

Nancy, Jean-Luc. Ser singular-plural. Madrid: Arena Libros, 2006

Piketty, Thomas. El capital en el siglo XXI. México: Siglo XXI Editores, 2014. Rancière, Jacques. El desacuerdo. Filosofia y política. Buenos Aires: Nueva Visión, 1996.

"Communism without Communism?". The Idea of Communism. Costas Douzinas and Slavoj Zizek (eds.). New York: Verso, 2010. 16777.

Schürmann, Reiner. El principio de anarquía. Heidegger y la cuestión del actuar. Madrid: Arena Libros, 2017.

Svampa, Maristella. “'Consenso de los Commodities'y lenguajes de valoración en América Latina". Nueva Sociedad 244, (Marzo-Abril) 2013. 30-46.

Viciano Pastor, Roberto y Rubén Martínez Dalmau. “¿Se puede hablar de un Nuevo Constitucionalismo Latinoamericano como corriente doctrinal sistematizada?". Ponencia presentada en el VIII Congreso Internacional de Derecho Constitucional, Ciudad de México. Valencia: Universitat de Valencia. 2010.

Villalobos-Ruminott, Sergio. Soberanías en suspenso. Imaginación y violencia en América Latina. Buenos Aires: La Cebra, 2013. 